\title{
Regulação em saúde no setor privado: o caso da ANS no Brasil e da ERS em Portugal
}

I ${ }^{1}$ Isabelle Maria Mendes de Araujo, ${ }^{2}$ Dmitri Felix do Nascimento,

${ }^{3}$ Angela Maria Pereira I

Resumo: No Brasil, o Sistema Único de Saúde (SUS) vem se consolidando enquanto um subsistema público de saúde que convive com um sólido subsistema privado de saúde suplementar e complementar. O sistema de saúde português, de forma semelhante, caracteriza-se pela presença de três subsistemas assistenciais: o Serviço Nacional de Saúde, um setor de seguros privados e um setor privado em ascensão. Para ambos os países, a questão do setor privado é um dilema e um desafio para as suas respectivas entidades reguladoras, a Agência Nacional de Saúde Suplementar (ANS) e a Entidade Reguladora da Saúde (ERS). Desse modo, objetiva-se compreender como as instituiçóes reguladoras atuam sobre o setor privado, demonstrando o crescimento desse setor, a segmentação dos sistemas de saúde, e o perfil de reclamaçôes dos beneficiários/utentes. Para tal, realizouse uma sistematização da literatura, levantamento dos gastos em saúde na base da OCDE, IBGE, ANS e ERS. Percebe-se que, com a consolidação de um padrão de empresariamento privado da saúde, inicia-se uma disputa por segmentos de clientela e especializaçôes; o fortalecimento do setor privado preserva suas bases de financiamento público mediante sua presença marcante e cada vez mais organizada nas arenas decisórias públicas, com o Estado, e nos fluxos do mercado.

> Palavras-chave: Mercado; gasto público; Estado.

\author{
1 Doutora em Saúde Coletiva, \\ Universidade Federal do Rio \\ Grande do Norte. Natal-RN, Brasil \\ (isabellesaudelivre@hotmail.com). \\ ORCID: 0000-0001-9732-2003 \\ ${ }^{2}$ Doutor em Ciência Política, \\ Instituto de Ciências Sociais, \\ Universidade de Lisboa. Lisboa, \\ Portugal (dmitri_felix@hotmail.com). \\ ORCID: 0000-0002-8436-9600 \\ ${ }^{3}$ Mestre em Serviço Social, \\ Universidade Federal da Paraíba. \\ João Pessoa-PB, Brasil (fisiot. \\ angelapereira@yahoo.com.br). \\ ORCID: 0000-0003-2603-7939
}




\section{Introdução}

Ao percorrermos a literatura, nota-se a nítida polissemia do termo regulação. Entretanto, é na área econômica que o mesmo encontra maior ressonância, como um instrumento de equilíbrio entre oferta e demanda, de modo a oferecer eficiência ao sistema com geração de resultados positivos. A utilização do processo regulatório como instrumento de gestão pode se tornar um potente equalizador social do sistema de saúde para amortizar a desigualdade relacional entre os entes público e privado, além de atenuar a relaçáo de necessidade, demanda e oferta, tornando-a coerente, compatível e sem grandes distorçôes (VILARINS et al., 2012).

A regulação torna-se uma resposta à realidade concorrencial do mercado em determinados setores de atividade. Com efeito, o modus operandi do mercado, em regra assente no interesse privatístico e no lucro distribuível, e distraído, por isso, do outro interesse, o de toda a população, fundamentou e fundamenta a intervenção pública. E, como é sabido, de uma abordagem pública de regulação passou-se, pouco a pouco, para uma intervenção através de entidades independentes com a missão de regular os mercados setoriais. $\mathrm{O}$ setor da saúde não passou ao largo desta tendência.

Segundo relatório da OCDE (2007): a configuração de reguladores autônomos é um desafio enfrentado por muitos países da OCDE à medida que modernizam seu arcabouço regulatório voltado para uma rede de prestação de serviços públicos e de oferta de serviços básicos que têm acesso universal ou cumpram funçôes sociais especiais, além da crescente rede privada de saúde. O objetivo é garantir a tomada de decisóes regulatórias independentes que possam ser protegidas dos interesses privados específicos e das consideraçóes políticas de curto prazo.

Ao comparar o setor de saúde de diferentes países, Eira (2010) sugere que existam diferenças substanciais, quer ao nível do grau de desenvolvimento do sistema de saúde, quer nas relações entre o setor público e privado; diferenças estas que, de acordo com o relatório da OMS, seriam motivadas (1) pelos valores da sociedade e pelo contexto cultural e histórico de cada país (aspectos políticos, econômicos e sociais) que influenciam o sistema de saúde, (2) pelos objetivos de saúde estabelecidos por cada um e respectiva ordem de prioridades definidas e (3) pelo próprio funcionamento do sistema de saúde, dos seus recursos/gastos, da forma ou do processo como se combinam e dos resultados na saúde das populaçôes. 
De acordo com Bravo (2010), modificaçôes e alteraçóes no Projeto de Saúde Democrática começam a ocorrer no Brasil e em Portugal a partir dos anos 1990, com a influência das agências internacionais que indicaram a necessidade de contrarreforma do Estado e das políticas de ajuste econômico. O fenômeno New Public Management, adotado como princípio no processo de reforma do governo britânico no período de 1997-2007, parece muito ter influenciado o modelo gerencial dos países estudados. Sucessivamente, entre 2002 e 2004, em Portugal, com o objetivo de melhorar a eficiência, foram aprovadas algumas normas dirigidas a reforçar o sistema de saúde misto, baseado nos pressupostos de complementaridade entre o setor público, social e privado (SERAPIONI; SESMA, 2011). No Brasil, nos anos 1990 fora apresentado o plano de Reforma do Estado com o discurso de reformar a gestáo pública, com criação de leis, como a das organizaçôes sociais, aplicadas também à saúde, conhecidas como novos modelos de gestáo, com objetivo de potencializar a eficiência do setor público (BARSOSA; ELIAS, 2010).

Em Portugal, as principais alteraçóes no Sistema Nacional de Saúde seriam: relativas à responsabilidade conjunta pela saúde, ou seja, dos cidadãos, da sociedade e do Estado (antes era principalmente do Estado); criação de seguro-saúde; estabelecimento de taxas moderadoras a serem cobradas pelo SNS, o qual muda seu status para tendencialmente gratuito; e a flexibilização da gestão dos serviços podendo ser desenvolvida por meio de convênios e cooperativas médicas através da prestação de serviços privados no setor público (BRAVO, 2010).

No Brasil, as contrarreformas na saúde nos anos 1990 foram: contenção dos gastos com racionalização da oferta por meio de políticas focais através do pacote básico para a saúde; estímulo ao seguro privado; descentralização dos serviços em nível local; subfinanciamento da saúde. Para Bravo (2010), a denominação mais adequada é "contrarreforma", pois as mesmas vão na direção de supressão de direitos, enquanto as reformas têm sua origem nas lutas sociais e progressistas.

Questiona-se qual o significado de sistemas completos, ou seriam parciais, de seguridade social pública e universal e que tipo de intervenção do Estado pode ser considerada socialmente apropriada e justa diante do crescente setor privado na saúde. Nesse sentido, objetiva-se compreender como as instituiçôes reguladoras de saúde do Brasil e de Portugal, respectivamente a ANS e a ERS, atuam sobre o setor privado, demonstrando o crescimento do setor, a segmentação dos sistemas de saúde e o perfil das reclamaçôes dos beneficiários/utentes aos serviços privados de saúde. 
Para tal, foi realizada uma revisão na literatura sobre a temática da regulação e dos sistemas de saúde, com ênfase sobre o setor privado de saúde do Brasil e de Portugal; também sistematizamos dados das próprias agências reguladoras ANS e ERS acerca do perfil das demandas dos beneficiários do setor suplementar, além de traçarmos o perfil dos gastos em saúde, público e privado, de ambos países no período de 2007 a 2015 a partir da base de dados da OCDE e da conta-satélite de saúde do IBGE.

\section{Segmentação do sistema de saúde do Brasil e de Portugal: o setor privado}

Ao considerar o setor de saúde do Brasil e de Portugal, os estudos apontam a fragmentação dos sistemas. Nem o Sistema Nacional de Saúde (SNS) português nem o Sistema Único de Saúde (SUS) brasileiro constitui-se enquanto um sistema único e estatal; em ambos, há subsistemas/segmentos. No Brasil, o SUS pensado como um sistema de cobertura universal vem se consolidando como um subsistema público de saúde que convive com um sólido subsistema privado suplementar e um outro subsistema privado de desembolso direto (MENDES, 2013). O sistema português se caracteriza pela copresença de três subsistemas assistenciais: o Serviço Nacional de Saúde, um setor de seguros privados e um consistente setor privado financiado pelo desembolso direto familiar (BARROS; SIMÓES, 2007).

Para a compreensão da segmentação dos sistemas de saúde, Thomson e Mossialos (2006) observam três modalidades de relação público e privado segundo o papel do setor privado e a extensão de sua cobertura: o papel de substitutivo, com a extensão da cobertura direcionada a pessoas que foram excluídas de algum ou de todos os benefícios da cobertura pública, como a opção de escolha entre cobertura pública ou privada para famílias de alta renda; de complementar, refere-se a serviços excluídos da cobertura pública, tais como de odontologia e/ou oftalmologia, ou serviços muito caros que são parcialmente cobertos pelo Estado; e de suplementar, refere-se à liberdade de escolha dos provedores e ao usufruto de acesso aos serviços por beneficiários.

O Brasil implementou um sistema de saúde público e universal tardio, numa conjuntura internacional adversa, no que se refere quer ao papel do Estado na provisão de benefícios sociais universais resultante de direitos de cidadania social, quer a políticas econômicas baseadas no desenvolvimento nacional. Estas foram 
substituídas pela globalização econômica, por tendências neoliberais de liberalização do mercado e pela não interferência do Estado no mercado, com exceção das salvaguardas necessárias à sua otimização, do financiamento do próprio mercado (GERSCHMAN, 2008).

Segundo Santos e Gerschman (2004), à época da criação do SUS houve articulaçóes claras do empresariado da medicina para ofertar planos simplificados ao Estado. Aquele era um momento de grande vácuo nas propostas para a atenção à saúde pública e de crise nas bases de financiamento pela retração da contribuição da Previdência Social para o financiamento da saúde. O sistema público se precipita em franca deterioração, que se expressa em sérios problemas de estrutura, aparelhamento e instalaçóes e em enormes dificuldades no acesso; ao tempo que o setor privado cresce sem nenhum tipo de controle e em aberta sobreposição aos serviços de atenção à saúde do SUS.

$\mathrm{Na}$ Constituição Cidadã brasileira de 1988, evidencia-se o papel desempenhado pelo setor privado no sistema de saúde e antecipam-se as dificuldades jurídicas e de governabilidade que o SUS terá para definir o lugar dos planos privados no recém-criado Sistema Único de Saúde. No art. 199 há que: "As instituiçôes privadas poderão participar de forma complementar do sistema único de saúde, segundo diretrizes deste mediante contrato de direito público ou convênio, tendo preferência as entidades filantrópicas e as sem fins de lucro. Ao mesmo tempo, no artigo 199 diz-se que: a saúde é livre à iniciativa privada".

Segundo Santos (2009), a expansão do setor privado no Brasil deve-se principalmente às desoneraçóes fiscais a prestadores privados e consumidores dos seus serviços; ao gasto de órgãos públicos com prestadores privados para a assistência à saúde de seus trabalhadores e familiares e ao uso de serviços do SUS por segurados com contrato para os serviços utilizados, quando náo ocorre o ressarcimento pelas operadoras ao sistema público. Para Gerschman (2008), as relaçôes público-privadas de financiamento da saúde reforçam uma tendência à segmentação da atenção à saúde e ao favorecimento indireto do setor privado pelo SUS.

A seguir, percebe-se o crescimento do número, em milhões, de beneficiários de planos privados no Brasil entre os anos 2000 e 2016, representando tendência decrescente a partir de 2015, figura 1 . 
Figura 1. Crescimento do setor de planos privados, por mil beneficiários ao ano, Brasil

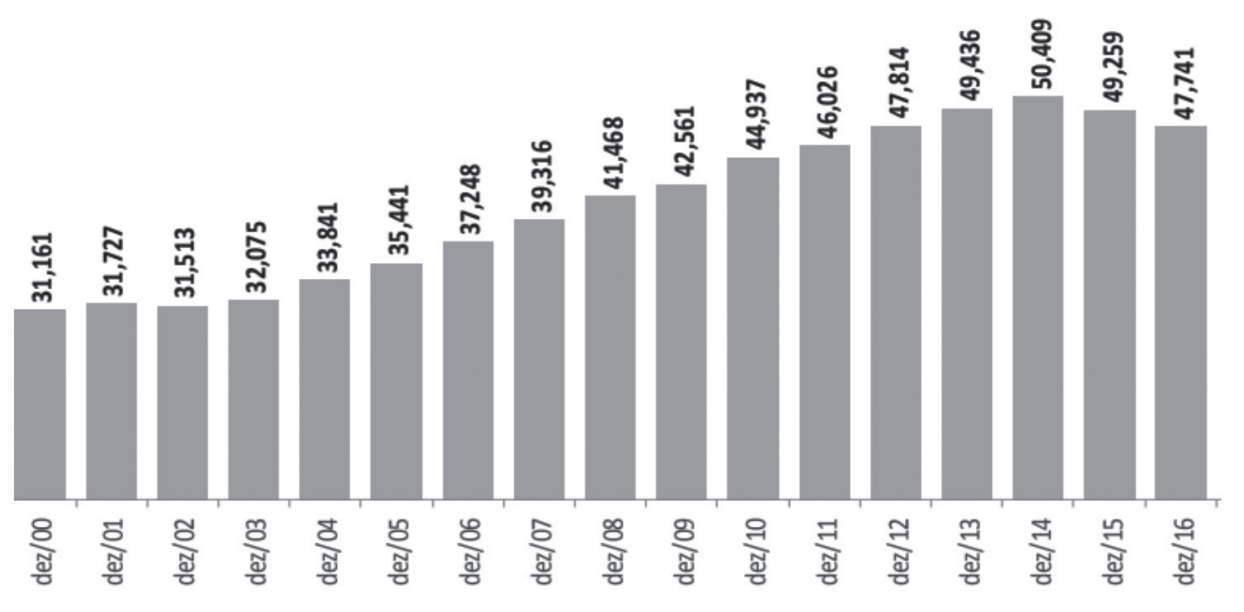

Fonte: ANS (2017).

Por outro lado, a Constituição Democrática Portuguesa de 1976 impôs que o acesso dos cidadãos aos cuidados no âmbito do Sistema Nacional de Saúde (SNS) é assegurado em respeito aos princípios fundamentais da universalidade, generalidade e gratuitidade tendencial. Ancorado no pilar da seguridade social, possibilitou aos portugueses a garantia do acesso à saúde; todavia, desde os anos 2000 vem sofrendo ataques decorrentes da crise do capital, com repercussão para o Estado de Bem-Estar Social, viabilizando o fortalecimento do setor privado.

Oliveira (2010) aponta cinco características específicas do sistema de saúde português como determinantes para o desenvolvimento da oferta privada: (1) a mobilidade do pessoal do SNS para o setor privado, (2) a possibilidade de os médicos aumentarem o seu rendimento através de atividade no setor privado, (3) os incentivos à criação de unidades privadas e a contratualização com o setor privado pelo setor público desde os anos 90, (4) a criação de vários programas especiais de recuperação de listas de espera (tendo o setor público recorrido à contratualização privada em alguns destes programas) e (5) o sistema de deduçôes fiscais para gastos em saúde.

Em Portugal, mantêm-se subsistemas públicos substitutivos ao SNS, enquanto entidade financiadora, a exemplo de serviços de alguns sindicatos, como a ADSE - Direção-Geral de Proteção Social aos Funcionários e Agentes da Administração Pública. Os subsistemas privados apresentam complementaridade (em termos de 
financiamento) ao SNS - os quais funcionam quase que numa lógica de seguros de saúde, através dos quais os cidadãos, que a eles aderem, de forma compulsiva ou voluntária, beneficiam-se de uma mais ampla cobertura, podendo ainda beneficiar-se de tratamento em estabelecimentos privados detidos por esses subsistemas (ERS, 2015).

Além disso, há o mercado dos seguros privados, caracterizado pelo número de indivíduos cobertos em seguros de saúde individuais e de grupo, que tem apresentado crescimento, chegando a quase dois milhóes e 200 mil o número de segurados em 2013, ou seja, 21\% da população residente em Portugal. Em 2013, o financiamento do setor privado tinha sido de $34 \%$, dos quais $28 \%$ foi de pagamentos direitos das famílias (out-of-pocket) (ERS, 2015).

Relativamente aos seguros, a Lei de Bases da Saúde de Portugal considera $o$ estabelecimento e exploração de seguros de saúde uma atividade complementar à própria prestação de cuidados de saúde, colocando-a sob a disciplina e inspeção do Ministério da Saúde, na medida em que a mesma se destina a facultar meios materiais ou de organização indispensáveis àquela prestação. Por outro lado, e como forma de fomentar essa tal complementaridade, a Base XLII da mesma LBS prevê que a Lei fixe incentivos ao estabelecimento de seguros de saúde.

$\mathrm{Na}$ perspectiva do financiamento, há, portanto, a componente pública e a componente privada, sendo a primeira predominante no sistema de saúde português. Com efeito, no período compreendido entre 2000 e 2008, a componente pública atingiu o seu máximo de $73,3 \%$ do financiamento da despesa corrente em saúde. Não obstante a primazia da parcela pública no financiamento, tem-se verificado ligeira redução do seu peso relativo no financiamento total a partir de 2004, contrabalançada por um pequeno acréscimo na expressividade da componente privada. Por sua vez, a componente privada agrega, essencialmente, quatro categorias: despesa privada das famílias; seguros privados; subsistemas de saúde privados; instituições sem fins lucrativos (ERS, 2015).

No gráfico 1, apresenta-se o perfil dos gastos em saúde em relação às despesas com consumo final de bens e serviços de saúde do percentual do Produto Interno Bruto (PIB) dos países Brasil e Portugal (2007-2015), por setor (público e privado), de acordo com a OCDE e IGBE (Conta-Satélite de Saúde). Observa-se no caso brasileiro a prevalência dos gastos privados e que, apesar da pouca variaçáo anual, houve um crescimento dos gastos em saúde na ultima década. O PIB total em 
saúde saiu de 8,5\% em 2007 para 9,1\% em 2015 (IBGE, 2017). Em Portugal, os gastos públicos são prevalentes; todavia, nota-se um decrescimento a partir de 2010; podendo estar associado aos planos de austeridade do país pós-crise de 2008.

\section{Gráfico 1. Gasto em Saúde, por setor e ano, Brasil e Portugal}

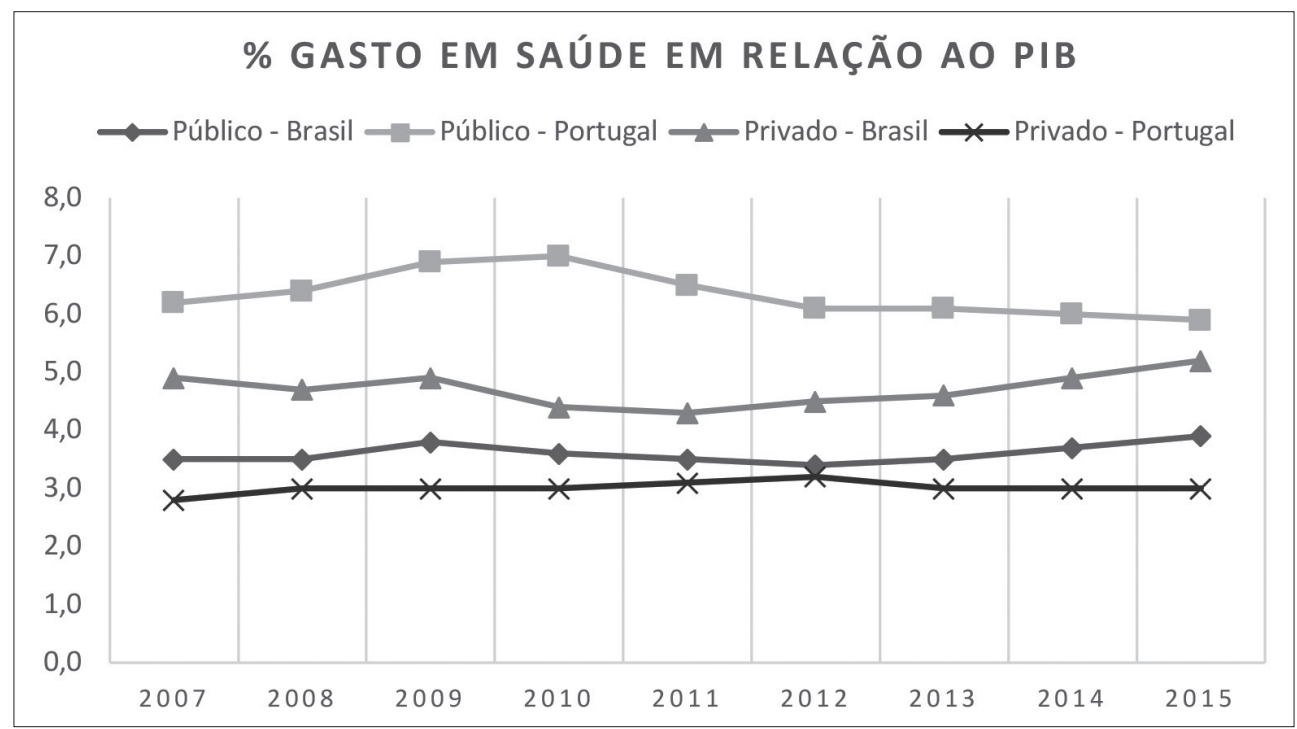

Fonte: IBGE/OCDE (2015).

Ao compararmos Brasil e Portugal quanto ao gasto por PIB com saúde e per capita, encontramos que há maior gasto público em Portugal: em 2010, Portugal destinou 10\% do PIB para o setor de saúde, o Brasil, $8 \%$; este com valor per capita total (US\$) de 900 e Portugal de US\$ 2.600 no mesmo ano (OCDE, 2015).

Segundo Mossialos e Thomson (2006), existem apenas duas concepçôes de políticas de financiamento no que se refere às modalidades apresentadas, a saber, o financiamento mínimo e regulação considerável do mercado suplementar focada na solvência das empresas; e o controle de preços e produtos e regulação severa aplicada ao mercado substitutivo. Em ambas as modalidades, pretende-se, de uma parte, proteger os consumidores da insolvência das seguradoras e, de outra, se valer da regulação para garantir o acesso a cuidados de saúde. Diferentemente, no que se refere à saúde complementar, os governos fazem livre escolha das formas mais apropriadas de subsidiar e de regular serviços privados em cada contexto nacional. 
No primeiro caso, o seguro privado comercializa planos de saúde que oferecem serviços já cobertos pelo sistema público de cunho universal ou pelo seguro social de adesão compulsória. $\mathrm{O}$ que caracteriza essa forma de inserção do seguro privado é, portanto, a cobertura duplicada de serviços de saúde que dele decorre. Isso não impede que, em alguns casos, o seguro privado suplementar ofereça alguns elementos adicionais, tais como diferenciação na hotelaria, livre escolha de prestador e/ou acesso mais ágil que no sistema estatutário. Ele também pode eventualmente prover alguns serviços não cobertos pelo sistema estatutário e que não são considerados como fundamentais para a saúde-por exemplo, cirurgia estética. O seguro suplementar está presente em diversos países, tais como Reino Unido, Irlanda, Finlândia, Portugal, Espanha, Itália e Grécia (MOSSIALOS; THOMSON, 2006).

Nesse sentido, pode-se dizer que ainda que a maioria dos países opere sistemas de cobertura universal, estes, nos dias de hoje, tendem a ser universais apenas nos princípios. Para quem procura asilo ou é imigrante, a cobertura de cuidados de saúde pode ser inexistente na prática. A erosão da cobertura do sistema público de saúde para oftalmologia e cuidados dentários é crescente. Ao distinguir seguro privado de saúde enquanto alternativa parcial ao sistema público (definido no artigo 54,1 da Comissão de Justiça da União Européia), a dificuldade parece residir em identificar em que situação os seguros privados desempenham um papel substitutivo e quando isto não acontece (GERSCHMAN, 2008).

\section{O papel da ANS e da ERS na regulação: os beneficiários/utentes}

A regulação do Estado no setor privado ocorre há muito tempo e de diversas formas. Inclusive, há muitas divergências entre os conceitos de regulação e regulamentação, sendo que ambas são realizadas pela administração direta, ou ainda mais recentemente, por novos arranjos institucionais.

Segundo Vilarins et. al. (2012), há influência da OCDE sobre os países latinos nas formas de regulação adotadas, inclusive no Brasil, e apresentam-se três categorias da atividade regulatória: Regulação Econômica - caracteriza-se pela intervenção direta nas decisóes de mercado, tais como definição de preços, competição, entrada e saída de novos agentes nos mercados; Regulação Social - destina-se a proteger o interesse público nas áreas de saúde, segurança, meio ambiente e em questôes 
nacionais; e Regulação Administrativa - destina-se a estabelecer os procedimentos administrativos por meio dos quais o governo intervém nas decisóes econômicas, os chamados red-tapes. O Estado intervém também na organização administrativa do setor privado. Nesse sentido, a dimensão do problema que se coloca é a formulação de políticas regulatórias para a esfera de planos e seguros privados de saúde, setor definido ora como complementar, ora como suplementar ao SUS e ao SNS.

$\mathrm{Na}$ década de 1990, houve no Brasil um crescimento do interesse do mercado privado, devido à política de privatização das estatais. Frente a este novo modelo de Estado com crescente setor privado, o governo lançou mão das Agências Reguladoras (AR) para que estas regulassem os segmentos privatizados. Desta forma, a normatização das concessôes, ou mesmo a fiscalização do setor que presta serviços típicos do Estado, também passa a ser regulado pelas AR (BAHIA, 2001).

Ao mesmo tempo que o Estado brasileiro, através da Constituição Federal de 1988, universalizou o sistema de saúde, possibilitou a atuação do setor privado, com regulamentação posterior por meio da Lei 9.656, de 1998. Da mesma forma, utilizou o recurso de uma agência reguladora para regulamentar o mercado de Saúde Suplementar, a partir de 2000.

A Câmara dos Deputados aprovou a Lei n. 9.656/98 para reger os planos privados, que obrigou, entre outras coisas: atendimento para todas as doenças relacionadas no Código Internacional de Doenças; proibição de negação de cobertura em função de doenças ou lesôes preexistentes; ressarcimento pelas operadoras dos atendimentos prestados a seus clientes na rede vinculada ao SUS (BAHIA, 2001).

A ANS, Agência Nacional de Saúde Suplementar, foi criada como órgão regulador autárquico especial no âmbito do Ministério da Saúde no Brasil, dispondo de diversos instrumentos jurídicos para fazer valer suas decisôes relacionadas com a própria estrutura da agência. A Lei 9.961/2000 cria a ANS e define a sua finalidade, estrutura, atribuiçôes, receita, natureza e vinculação. A regulação exercida pela agência possui papel fundamental no cumprimento das políticas determinadas pelo Estado e sua função legal é gerencial (técnica), de controle e fiscalização sobre os entes regulados no setor de saúde suplementar. A ANS tem como missão legal promover a defesa do interesse público na assistência suplementar à saúde, regular as operadoras setoriais inclusive quanto às suas relaçôes com prestadores e consumidores - e contribuir para o desenvolvimento das ações de saúde no país (PIETROBON, et al., 2008). 
Com a criação da ANS, as funçôes a serem exercidas seriam: a combinação de estratégias coercitivas e cooperativas para as empresas que atuam no setor econômico, orientadas ou não para o mercado; a aceitação de que a competição pode gerar equilíbrio nas decisões econômicas e favorecer o direito de consumidores, e que as condutas responsáveis das empresas podem trazer benefício público (externalidade positiva); o desenvolvimento de estratégias cooperativas entre as estruturas institucionais do SUS (Sistema Único de Saúde) e os segmentos da saúde supletiva, diante da atenção de alto custo e de longa duração; o acompanhamento e a avaliação das orientaçóes redistributivas, como o ressarcimento ao SUS (PIETROBON, et al., 2008).

Malta et al. (2004) identificam três ênfases na atuação da ANS: 1) a regulação financeira das operadoras; 2) quanto ao direito dos consumidores, contratos e relaçóes de consumo; e 3) sobre os produtos visando ao controle do preço da assistência à saúde. Dessa forma, surge nesse ponto o primeiro grande conflito de interesse entre os participantes desse mercado: a ANS, procurando defender os usuários de planos de saúde que são certamente a parte mais fraca na relação com as operadoras. Em estudo, GERSCHMAN et al. (2012) ressaltam que, do ponto de vista mercantil, as operadoras funcionam como é de se esperar, maximizando renda. Contudo, por serem os serviços hospitalares bastante diferenciados de outros serviços públicos, as operadoras deveriam exigir do prestador boa qualidade do que é contratado. Mas os resultados da pesquisa são claros a respeito da ausência de regulação quanto à qualidade da assistência exigida pela operadora na sua relação com os prestadores hospitalares.

No Brasil, segundo Bahia e Viana (2002), há um problema das políticas regulatórias, que se agrava ao considerarmos que o parque hospitalar privado não foi criado como "complementar" ao sistema público, mas fundamentalmente para dar conta de um "nicho de mercado" em que o setor público era deficitário. Os planos privados mostram o crescimento sistemático de beneficiários, chegando hoje a uma cobertura de mais de $25 \%$ da população. Ressaltam-se as barreiras de acesso relativas à coexistência de seguros privados, dando cobertura aos mesmos serviços do SUS, sobretudo no que se refere à atenção ambulatorial. Os planos constituem grave problema para o SUS e para o usuário que paga ao seguro por um serviço que, por vezes, é coberto pelo próprio sistema público.

Em pesquisa relativa à satisfação de beneficiários de planos privados de hospitais filantrópicos, aponta-se a utilização ilegítima do SUS no encaminhamento de pacientes com planos de preço e qualidade inferiores. Esta prática, além do mais, não 
é acompanhada pelo ressarcimento dos planos ao SUS, ao tempo que indiretamente o setor público subsidia os planos privados e fortalece a segmentação do sistema (GERSCHMAN, 2008). Considera-se que há um uso múltiplo do sistema público. Nesse sentido, a política de "olhos bem fechados" possibilita a utilizaçâo do SUS pelas operadoras, ao facilitar a dupla porta de entrada de pacientes beneficiários de planos nos hospitais privados contratados pelo plano e conveniados com o SUS.

Um papel relevante da ANS é a regulação sobre a cobrança do ressarcimento ao SUS, questão em que a agência vem enfrentando algumas dificuldades. A ANS cruza os dados dos sistemas de informaçóes do SUS com o Sistema de Informaçóes de Beneficiários (SIB) da própria agência para identificar os atendimentos a beneficiários de planos de saúde; todavia, os planos apresentam pendências para a implantação/alimentação do sistema. A ANS procede à notificação, cobrança e repasse ao Fundo Nacional de Saúde; os valores passíveis de ressarcimento são os atendimentos ambulatoriais de alta complexidade e as internações hospitalares. Entre 2000 e 2010, a ANS arrecadou mais de R 120 milhóes, valor considerado ainda distante do real uso duplicado pelo setor privado (ANS, 2012).

Em 18 anos de operação da ANS, destacam-se os seguintes avanços:

- a criação do Programa de Qualificação como instrumento de avaliaçáo com indicadores distribuídos em quatro dimensóes (atenção à saúde, econômicofinanceira, estrutura e operação, e satisfação dos beneficiários);

- o Índice de Desempenho da Saúde Suplementar;

- o aperfeiçoamento da regulaçáo indutora e normativa da ANS;

- a indicação da importância do Sistema de Informação como insumo estratégico de análise e tomada de decisão, tornando o setor mais transparente;

- açóes efetivas das operadoras na melhoria da qualidade dos dados informados;

- ampliação do debate sobre modelo de atenção à saúde; adoção de ações de promoção à saúde e prevenção de doenças;

- ampliação da agenda para incorporação e avaliação das tecnologias em saúde; aproximação com os órgãos de Defesa do Consumidor, através da realização de fóruns para melhor conhecimento da estrutura e funções da ANS e dos aspectos da legislação do setor.

O Índice de Desempenho da Saúde Suplementar (IDSS) 2015 é composto pela avaliação da assistência prestada pelas operadoras aos seus clientes (Atenção à Saúde), 
quesito que equivale a $40 \%$ da composição da nota, além de indicadores de satisfação do cliente (20\%), estrutura e operação da empresa (20\%) e aspectos econômicofinanceiros (20\%). Além do desempenho das operadoras, o IDSS permite avaliar a distribuição percentual de operadoras médico-hospitalares e odontológicas por faixas de pontuação, bem como dos beneficiários, entre outros recortes. $\mathrm{O}$ escore varia de 0 a 1 , sendo 1 o nível de melhor desempenho.

Além disso, com a finalidade de dar transparência a informaçóes sobre as queixas registradas por beneficiários junto aos canais de relacionamento da ANS e de possibilitar à sociedade saber de que forma as operadoras de planos se comportam diante dessas demandas, a ANS disponibiliza três indicadores que permitem comparar a atuação das empresas que atuam no setor de saúde suplementar: o Índice Geral de Reclamaçōes (número médio de reclamaçōes a cada dez mil beneficiários), o Percentual de Finalização Assistencial (percentual de demandas resolvidas entre beneficiários e operadoras) e o Índice de Abertura de Processo Administrativo (número médio de demandas com indicativo de infração que foram encaminhadas para abertura de processo). Para cada indicador, há gráficos sobre o desempenho do setor e das operadoras, a natureza e os temas das demandas e um ranking com o total de operadoras por segmentação (médicohospitalar ou exclusivamente odontológica) e porte (pequeno, médio e grande), além da consulta individualizada por operadora (ANS, 2015).

$\mathrm{Na}$ figura 2, por exemplo, observa-se que na classificação das demandas de operadoras de grande porte quanto à sua natureza, $65 \%$ são de demanda assistencial, e quanto ao assunto mais recorrente, é o gerenciamento das açôes de saúde por parte da operadora, com $37 \%$.

Figura 2. Classificação das demandas das operadoras médico-hospitalares de grande porte

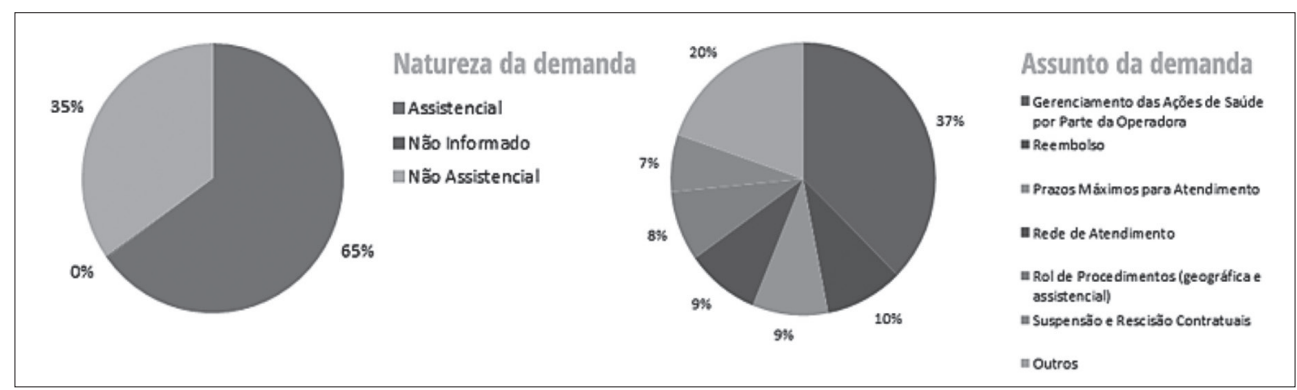

Fonte: ANS (2015). 
Desse modo, o modelo de regulação do setor de saúde suplementar brasileiro é diferenciado em relação à experiência internacional. $\mathrm{Na}$ maioria dos países, a regulação é feita a partir da atividade econômica em si, atuando sobre as empresas do setor e garantindo suas condiçôes de solvência e a competitividade do mercado. No Brasil, optou-se por regular fortemente o produto oferecido, ou seja, a assistência à saúde, com medidas inovadoras como a proibição da seleção de risco e do rompimento unilateral dos contratos, preservando a competitividade do mercado.

O caso do sistema de saúde português pode ser analisado numa dupla perspectiva: do financiamento e da prestação dos cuidados de saúde. Na perspectiva financiamento, é possível distinguir o SNS financiador, os subsistemas privados financiadores e os seguros de saúde, bem como o pagamento direto pelos indivíduos e pelas famílias (também designado por out-of-pocket), no qual os planos de saúde se enquadram. Na perspectiva da prestação, identificam-se as situações de prestação pública (assegurada através de estabelecimentos integrados no SNS ou através de estabelecimentos sociais e privados que foram contratados para a sua realização) e de prestação social ou privada (OLIVEIRA, 2010).

De acordo com o Eurostat 2015, Portugal é um dos países em que as necessidades não atendidas de exame médico mais subiram, principalmente a partir de 2011, integrando o grupo da Grécia e Espanha. De acordo com os dados do Instituto Nacional de Estatística português, tem havido um decréscimo constante no total de leitos oferecidos pelo SNS, ao mesmo tempo que se verifica um incremento, também constante, das leitos oferecidos pelos hospitais privados (ERS, 2015).

Em Portugal, a função de regulação independente do setor é atribuída à ERS, Entidade Reguladora da Saúde, criada pelo Decreto-Lei 309/2003. Já nessa data surgiu como uma autoridade de supervisão e regulação de todo o setor da saúde (público e privado), independente no exercício das suas funçôes, com a atribuição de regular a atividade dos operadores privados e sociais no âmbito da prestação dos serviços públicos, com especial ênfase na garantia dos direitos relativos ao acesso aos cuidados de saúde e dos demais direitos dos utentes - como são chamados em Portugal os usuários do sistema de saúde -, a legalidade e transparência das relaçôes econômicas entre os diversos operadores, entidades financiadoras e utentes. Atualmente, as atribuiçôes, organização e funcionamento da ERS estão previstos no Decreto-Lei 126/2014. 
A Lei n. 24/96, de 31 de julho - que aprovou o regime legal aplicável à defesa do consumidor (comumente designada por Lei do Consumidor), ao definir como consumidor "aquele a quem sejam fornecidos bens, prestados serviços ou transmitidos quaisquer direitos, destinados a uso não profissional, por pessoa que exerça com carácter profissional uma actividade económica que vise a obtenção de benefícios" - implicou que o utente assumisse a qualidade de consumidor na relação jurídicoprivada originada com o prestador de cuidados em saúde.

Os objetivos da regulação da ERS no setor são assegurar o direito de acesso universal e igual a todas as pessoas ao serviço público de saúde; garantir adequados padrôes de qualidade dos serviços; assegurar os direitos e interesses legítimos dos utentes e a legalidade e transparência nas relaçóes econômicas que se geram entre todos os agentes do sistema; realizar sançóes e, ainda, promover e defender a concorrência no mercado, ainda que em cooperação com a Autoridade da Concorrência. Contando com o Sistema de Registo de Estabelecimentos Regulados, tanto do setor público como do setor privado (ERS, 2014). Todavia, a modalidade de financiamento privado dos cuidados de saúde (seguros e planos) assume-se como "terra de ninguém" porque, no presente, não se encontra regulamentada em legislação específica (pois, desde logo, não se enquadra num setor de atividade específico) e, consequentemente, é fragilizada a regulação setorial (ERS, 2014).

Atendendo ao enquadramento em torno da Segurança do Doente, mencionase a atuaçáo da Entidade Reguladora da Saúde (ERS) na criação do sistema de avaliação e classificação dos estabelecimentos de saúde - o Sinas (Sistema Nacional de Avaliação em Saúde), um modelo de avaliação qualitativo dos estabelecimentos hospitalares do sistema, de adesão voluntária, que inclui a avaliação e publicação de indicadores de Segurança do Doente.

Desse modo, a ERS é, no quadro do setor da saúde, precisamente a "separação da função do Estado como regulador e supervisor, em relação às suas funçôes de operador e de financiador, mediante a criação de um organismo regulador e a atribuição de uma forte independência ao organismo regulador, de modo a separar efetivamente as referidas funçôes e a garantir a independência da regulação, quer em relação ao Estado operador quer em relação aos operadores em geral". Nesse quadro de independência, à ERS foram atribuídas competências de assegurar os direitos e interesses legítimos dos utentes e, nesse âmbito e entre outras competências, propor 
critérios básicos relativos à "Carta dos direitos dos utentes” dos serviços de saúde e proceder ao registro desta (ERS, 2014).

À luz das fontes internacionais e nacionais de direitos, é então possível identificar os "pilares" da Carta dos Direitos dos Utentes portuguesa: o direito de acesso, o direito à qualidade dos cuidados, o direito ao consentimento informado, direito à decisão, o direito à queixa e à reclamação e o direito a ser representado e a constituir associações de defesa dos seus direitos e interesses legítimos, o direito à prevenção da doença e à promoção da saúde (ERS, 2014).

Na perspectiva do direito à queixa e à reclamação, os estabelecimentos prestadores de cuidados de saúde devem enviar à ERS cópia das reclamaçôes e queixas dos utentes, designadamente as constantes dos respectivos Livros de Reclamaçóes.

Considerando que a Entidade Reguladora da Saúde (ERS, 2014) recebeu e investigou ao longo de anos recentes um número crescente de exposiçôes de beneficiários respeitantes a distintos aspectos dos cartóes de saúde, que se prendem designadamente com as cláusulas contratuais habitualmente firmadas pelas partes e a distinçáo entre aqueles e os seguros de saúde, tendo ainda ouvido um conjunto de queixas de prestadores de cuidados de saúde que se prendiam principalmente aos valores definidos nas tabelas de preços dos cartóes a pagar pelos utentes, foi deliberada a elaboração de um estudo para análise desta temática em diferentes dimensóes. Isso tendo em conta os direitos dos utentes e as implicaçóes destes planos no setor da prestação de cuidados de saúde. A ERS realizou o enquadramento legal e regulatório da atividade dos cartôes de saúde em Portugal sobre eventuais problemas de concorrência, acesso e qualidade dos cuidados dos planos privados.

Nesse sentido, ERS tem tomado conhecimento de inúmeras reclamaçôes em relação aos planos e aos cartôes de saúde que os titulam. Habitualmente, ali são denunciadas, designadamente, dificuldades na rescisão dos contratos celebrados e na devolução dos valores pagos a título de mensalidade, veiculação de uma informação deficitária a propósito dos benefícios associados e fácil confundibilidade com os seguros de saúde (ERS, 2014).

A ERS realiza a apreciação e monitorização do tratamento dispensado pelos estabelecimentos prestadores de cuidados de saúde, independentemente da sua natureza jurídica, às reclamaçôes de que são objeto. Com a disponibilização de uma plataforma eletrônica para inserção e tratamento de reclamaçôes a todos 
os estabelecimentos regulados pela ERS no Sistema de Gestão de Reclamaçóes (SGRec), no qual é permitido a operacionalizaçâo dos requisitos normalizados do regulamento.

Figura 3. Processo do Sistema de Gestão de Reclamaçôes (SGRec)

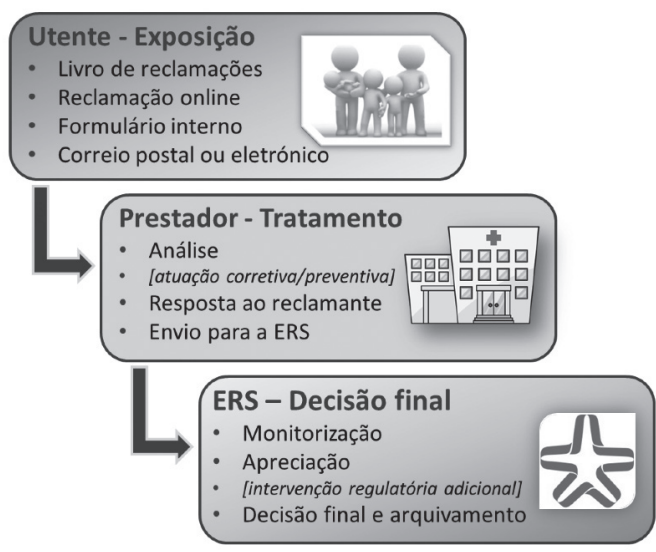

Fonte: ERS (2015).

Com o sistema, é possível visualizar o quadro das reclamaçóes por prestador e os temas/assuntos das mesmas em Portugal, figura 4 e tabela 2.

Figura 4. Reclamaçóes por natureza jurídica e tipo de prestador

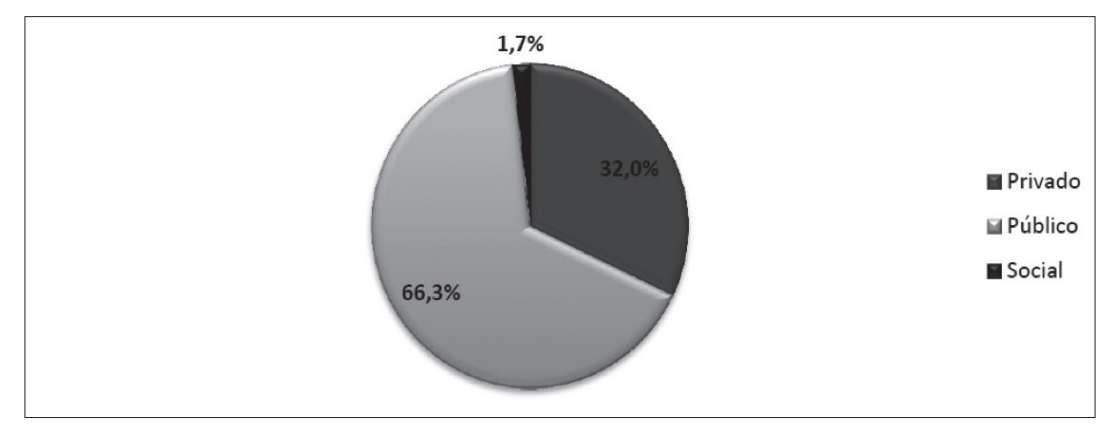

Fonte: ERS (2015). 
Tabela 2. Reclamaçốes por temas e assuntos visados

\begin{tabular}{|l|l|l|l|l|}
\hline \multicolumn{1}{|c|}{ Temas } & $\begin{array}{c}\text { Priv. cl } \\
\text { Intern. }\end{array}$ & $\begin{array}{l}\text { Priv. s/ } \\
\text { Intern. }\end{array}$ & $\begin{array}{l}\text { Pub. cl } \\
\text { Intern. }\end{array}$ & $\begin{array}{l}\text { Pub. s/ } \\
\text { Intern. }\end{array}$ \\
\hline Acesso a cuidados de saúde & 178 & 77 & 1551 & 1084 \\
\hline Cuidados de saúde e segurança do doente & 725 & 393 & 1803 & 420 \\
\hline Focalizaçáo no utente & 662 & 285 & 1784 & 416 \\
\hline Instalaçôes e serviços complementares & 218 & 52 & 606 & 156 \\
\hline Outros temas & 693 & 213 & 409 & 121 \\
\hline Procedimentos administrativos & 868 & 422 & 1304 & 684 \\
\hline Questóes financeiras & 439 & 185 & 693 & 158 \\
\hline Sugestão & 70 & 8 & 157 & 57 \\
\hline Tempos de espera & 1206 & 260 & 2722 & 218 \\
\hline Total Geral & 5059 & 1895 & 11029 & 3314 \\
\hline
\end{tabular}

Fonte: ERS (2015).

No relatório da ERS (2015) do primeiro trimestre daquele ano sobre reclamaçôes, observou-se que quanto ao tipo de prestador, 66,3\% das queixas são do setor público e $32 \%$ do setor privado. O tempo de espera é o tema mais mencionado em reclamaçóes visando prestadores com internamento, independentemente de se tratar de estabelecimentos do setor público ou não público. O setor privado reclama majoritariamente de procedimentos administrativos. Também em estudo da ERS, sobre os seguros de saúde, os motivos de insatisfação mais importantes são as coberturas dos seguros e exclusóes, bem como o preço dos seguros.

\section{Considerações finais}

Pode concluir-se, por um lado, que a crise que temos atravessado tem interferido no acesso aos cuidados de saúde, quer consideremos as dimensóes associadas à oferta, quer as associadas à procura; e por outro, que é essencial preservarmos o acesso aos referidos cuidados como forma de contribuir para a ultrapassagem da crise.

No caso de Portugal, com os pressupostos de persistência da política fiscal restritiva - com reduçáo do financiamento público das despesas em saúde, do aumento das despesas em saúde e do baixo crescimento econômico, os seguros e planos privados 
deverão continuar a apresentar crescimento no país, no médio prazo, como forma de financiamento complementar ao que deve ser garantido aos cidadãos pela prestação de cuidados de saúde pública e publicamente financiada.

A especificidade do caso brasileiro situa-se no papel que coube ao Estado no crescimento dos planos de saúde. Percebe-se um favorecimento indireto do aumento do número de beneficiários destes planos e a diminuição de cobertura que se explica pelas mazelas do setor público. Dentre elas, a perda da extensão universal da atenção à saúde, as dificuldades no acesso, os deficits de avaliação e controle adequados dos serviços de saúde, aliados à carência de financiamento e à utilização privada dos recursos públicos. A análise de resultados de pesquisas recentes evidencia a ausência de controle e avaliação da qualidade da atenção, infraestrutura e incorporação de tecnologias nos serviços privados conveniados com o SUS. Essas situaçóes reforçam uma tendência à segmentação da atenção à saúde e ao favorecimento indireto do setor privado pelo SUS.

Nesse sentido, nos questionamos como formular políticas de modo a deter a governabilidade de atores com interesses e papéis bem diferenciados num âmbito institucional capaz de exercer uma gestão integrada do sistema de saúde. $\mathrm{Na}$ ausência de controle e de avaliaçáo, os interesses se digladiam e, segundo resulte do enfrentamento e/ou composição, a esfera pública torna-se cinzenta e interpenetrada por interesses privados. ${ }^{1}$

\section{Referências}

AGÊNCIA NACIONAL DE SAÚDE SUPLEMENTAR. Anuário 2012. Aspectos econômicofinanceiros das operadoras de planos de saúde. Rio de Janeiro: ANS, 2012.

. Índice de Reclamaçōes das operadoras, 2015. Disponível em: <http://www.ans.gov.br/ espaco-da-qualidade/indice-de-reclamacoes>. Acesso: 20 set. 2015.

Perfil de crescimento dos beneficiários do setor suplementar no Brasil. Disponível em: <http://www.ans.gov.br >. Acesso: 20 jun. 2017.

BAHIA, L. O mercado de planos e seguros de saúde no Brasil: tendências pós-regulamentação. In: NEGRI, B.; DIGIOVANNI, G. Brasil: radiografia da saúde. Campinas: Instituto de Economia da Unicamp, 2001. p. 690-91.

BAHIA, L.; VIANA. A. Breve histórico do mercado de planos de saúde no Brasil. In: BRASIL. Ministério da Saúde. Regulação e saúde: estrutura, evolução e perspectivas da assistência médica suplementar. Rio de Janeiro: ANS, 2002. 
BARBOSA, N.; ELIAS, P. As organizações sociais de saúde como forma de gestão público/ privado. Ciênc. saúde coletiva. Rio de Janeiro, v. 15, n. 5, 2010.

BARROS, P.; SIMÓES, J. Portugal: Health system review. Health Systems in Transition, v. 9, n. 5, p. 1-140, 2007.

BRAVO, M. A saúde no Brasil e em Portugal na atualidade: o desafio de concretizar direitos. Serv. Soc. Soc. São Paulo, n. 102, p. 205-221, June 2010.

EIRA, A. A saúde em Portugal: a procura de cuidados de saúde privados. Tese (Mestrado em Economia) - Universidade do Porto, Porto, Portugal, 2010.

ENTIDADE REGULADORA DA SAÚDE. Os cartôes de saúde em Portugal, 2014. Disponível em: <https://www.ers.pt/pages/15 >. Acesso: 23 ago. 2015.

. Os seguros de saúde e o acesso dos cidadãos aos cuidados de saúde, 2015. Disponível em: <https://www.ers.pt/pages/15>. Acesso: 23 de agosto de 2015.

. Relatório sobre "A carta dos direitos dos utentes". 2011. Disponível em: <https://www.ers. pt/pages/15 >. Acesso: 23 de agosto de 2015 .

. Sistema de Gestão de Reclamaçôes. Jan-Jun/2015. Disponível em: <https://www.ers.pt/ pages/15>. Acesso: 23 ago. 2015.

GERSCHMAN, S. et al . O papel necessário da Agência Nacional de Saúde Suplementar na regulação das relaçóes entre operadoras de planos de saúde e prestadores de serviços. Physis: Revista de Saúde Coletiva. Rio de Janeiro, v. 22, n. 2, p. 463-476, jun. 2012.

GERSCHMAN, S. Políticas comparadas de saúde suplementar no contexto de sistemas públicos de saúde: União Européia e Brasil. Ciênc. saúde coletiva. Rio de Janeiro , v. 13, n. 5, p. 1441-1451, 2008.

INSTITUTO BRASILEIRO DE GEOGRAFIA E ESTATÍSTICA. Conta-satélite de saúde: Brasil 2007-2015. Rio de Janeiro: IBGE, 2017.

MALTA, D. C. et al. Perspectivas da regulaçấo na saúde suplementar diante dos modelos assistenciais. Ciênc. saúde coletiva. Rio de Janeiro, v. 9, n. 2, p. 433-444, abr./jun. 2004.

MENDES, E. 25 anos do Sistema Único de Saúde: resultados e desafios. Estudos avançados, São Paulo, v. 27, n. 78, p. 27-34, 2013.

MOSSIALOS, E.; THOMSON, S. Regulating private health insurance in the European Union: the implications of single market legislation and competition policy. LSE Health. Working Paper n.: 4/2006.

ORGANIZAÇÃO PARA A COOPERAÇÃO E DESENVOLVIMENTO ECONÔMICO (OCDE). Data Health resources. Disponível em: < https://data.oecd.org/healthres/healthspending.htm?context=OECD>. Acesso: 23 ago. 2015.

. Relatório sobre a Reforma Regulatória. BRASIL - Fortalecendo a governança para o crescimento. 2007. 
OLIVEIRA, M. Evolução da oferta. In: SIMÓES, J. 30 anos do serviço nacional de saúde. Coimbra: Almedina, 2010. p. 51-73.

PIETROBON, L. et al. Saúde suplementar no Brasil: o papel da Agência Nacional de Saúde Suplementar na regulação do setor. Physis Revista de Saúde Coletiva. Rio de Janeiro, v. 18, n. 4, p. 767-783, 2008.

SANTOS, I. O mix público-privado no sistema de saúde brasileiro: elementos para a regulação da cobertura duplicada. Tese (Doutorado em Saúde Pública) - Fundação Oswaldo Cruz, Rio de Janeiro, 2009.

SANTOS, M.; GERSCHMAN, S. As segmentaçôes da oferta de serviços de saúde no Brasil: arranjos institucionais, credores, pagadores e provedores. Ciênc. saúde coletiva. Rio de Janeiro, v. 9, n. 3, p. 795-806, set. 2004

SERAPIONI, M.; SESMA, D. A participação dos cidadãos nos sistemas de saúde dos países da Europa do Sul: Portugal, Itália e Espanha. Resultados preliminares de um estudo comparativo. Sociologia online, n. 2, p. 599-629, abr. 2011.

VILARINS, G. C. M. et al. A regulação em saúde: aspectos conceituais e operacionais. Saúde em Debate. Rio de Janeiro, v. 36, n. 95, p. 640-647, out./dez. 2012.

\section{Nota}

${ }^{1}$ I. M. M. de Araujo participou concepção, desenho e análise do estudo e revisão da redação do manuscrito. D. F. do Nascimento realizou análise e revisão final do manuscrito. A. M. Pereira realizou a revisão final do manuscrito. 


\section{Abstract}

Health regulation in the private sector: The case of ANS in Brazil and ERS in Portugal In Brazil, the Unified Health System (SUS) has been consolidated as a public health subsystem that coexists with a solid private subsystem supplementary and complementary health. The Portuguese health system, similarly, is characterized by the presence of three health subsystems: the National Health Service, private insurance and rising private sector. For both countries, the issue of the private health sector is a dilemma and a challenge to their respective regulators, the National Supplementary Health Agency (ANS) and the Regulatory Authority of Health (ERS). Thus, we aim to understand how regulatory institutions act on the private sector, demonstrating the growth of this sector, the segmentation of health systems, and the profile of complaints of beneficiaries. To this end, we carried out a systematic literature, survey of health expenditures on the basis of the OECD, IBGE, ANS and ERS. It With the consolidation of a pattern of private health business created a dispute over client segments and specializations; the private sector preserves its public funding base through its strong presence and increasingly organized in public decision-making arenas, with the State, and market flows.

Keywords: Market; public spending; State. 